\title{
An algorithm for the management of non-alcoholic fatty liver disease in primary care
}

\begin{abstract}
Background: Non-alcoholic fatty liver disease (NAFLD) encompasses a spectrum of conditions from simple hepatic steatosis to non-alcoholic steatohepatitis (NASH), a condition that includes fat accumulation, inflammation, and cell death. The single factor that predicts early death in patients with NASH is hepatic fibrosis. Hence, early identification and risk stratification of individuals with NASH and fibrosis is essential.

Methods: A panel comprising 11 liver disease specialists was assigned sections of the manuscript to present at a consensus meeting in December 2019. The goal was to develop a care pathway for primary care providers (PCPs) to identify patients at risk for NAFLD, stratify risk, and refer those in need of specialty services.

Results: We developed a simple algorithm to identify risk factors for NAFLD and recognize patients with progressive hepatic fibrosis. Patients with obesity, type 2 diabetes, abnormal liver tests, or incidental findings of hepatic steatosis should be evaluated for NAFLD, hepatic fibrosis and cardiovascular risk using family history and accepted calculators (FIB4 and ACC/AHA). Risk stratification includes cardiovascular and hepatic complications. Patients with $\geq$ stage 2 fibrosis by non-invasive testing should be referred to hepatologists. We recommend lifestyle interventions and medical management of comorbidities for patients with NAFLD. Patients should be followed long-term with assessment of liver status every 6 months.
\end{abstract}

Conclusions: Using this algorithm in a primary care setting may raise awareness of risk factors for NAFLD, encourage timely lifestyle interventions, promote appropriate prescribing habits, result in more effective use of specialist consultations, and improve patient outcomes.

Keywords: fatty liver, steatosis, liver disease, fibrosis, cirrhosis, metabolic syndrome
Volume 12 Issue 4 - 202I

\author{
Amreen Dinani,' Norman Sussman, ${ }^{2}$ \\ Mazen Noureddin, ${ }^{3}$ Michael Fuchs, ${ }^{4}$ \\ George Therapondos, ${ }^{5}$ Nigel Girgrah, ${ }^{5}$ \\ Viviana Figueroa Diaz, ${ }^{6}$ Parvez Mantry, \\ Mary Rinella, ${ }^{8}$ Amon Asgharpour, ${ }^{9}$ Douglas \\ Dieterich' \\ 'Department of Medicine, Icahn School of Medicine at Mount \\ Sinai, USA \\ ${ }^{2}$ Department of Medicine, Baylor College of Medicine, USA \\ ${ }^{3}$ Department of Digestive and Liver Diseases, Cedars-Sinai \\ Medical Center, USA \\ ${ }^{4}$ Department of Internal Medicine, Central Virginia VA Health \\ Care System and Virginia Commonwealth University, USA \\ ${ }^{5}$ Multiorgan Transplant Institute, Ochsner Health System, USA \\ ${ }^{6}$ Department of Medicine, New York University Langone \\ Medical Center, USA \\ ${ }^{7}$ The Liver Institute, Methodist Health System, USA \\ ${ }^{8}$ Department of Medicine, Northwestern University Feinberg \\ School of Medicine, USA \\ 'Department of Internal Medicine,Virginia Commonwealth \\ University, USA
}

Correspondence: Amreen Dinani, Icahn School of Medicine at Mount Sinai, I Gustave L. Levy PI., New York, USA, Tel 603-277-I445,Email amreen.dinani@mssm.edu

Received: August 04, 202। | Published: August 16, 202 |
Abbreviations: AASLD, american association for the study of liver diseases; ACC/AHA, american college of cardiology/american heart association; ADA, american diabetes association; ALT, alanine aminotransferase; APRI, AST to platelet ratio index; AST, aspartate transaminase; AUDIT, alcohol use disorders identification test; BARD, BMI, AST/ALT ratio, diabetes; BMI, body mass index; EASD, european association for the study of diabetes; EASL, european association for the study of the liver; EASO, european association for the study of obesity; ELF, enhanced liver fibrosis; FIB4, fibrosis-4 index; GLP-1, glucagon-like peptide-1; HbA1c, glycated haemoglobin A1c; HCC, hepatocellular carcinoma; NAFLD, nonalcoholic fatty liver disease; NASH, non-alcoholic steatohepatitis; NFS, NAFLD fibrosis score; NIT, non-invasive test; PCP, primary care provider; SGLT2i, sodium-glucose co-transporter-2 inhibitor; T2DM, type 2 diabetes mellitus; VCTE, vibration-controlled transient elastography

\section{Introduction}

Non-alcoholic fatty liver disease (NAFLD) is the most common cause of chronic liver disease and cirrhosis in the United States (US), affecting $25-33 \%$ of adults. ${ }^{1}$ The steady incline in NAFLD prevalence mirrors the growing obesity and type 2 diabetes mellitus (T2DM) disease burden. NAFLD is estimated to affect over one-third of the US population and over half of adults with T2DM. ${ }^{2,3}$ NAFLD is strongly associated with cardiovascular disease and non-hepatic cancers ${ }^{4,5}$ and recognized as a cause non-cirrhotic HCC. ${ }^{6}$ NAFLD has considerable burden on the US healthcare system accounting for $\sim 8 \%$ of all-cause mortality and $36 \%$ of liver disease-related deaths. ${ }^{7}$

NAFLD encompasses a spectrum of conditions, ranging from simple hepatic steatosis (accumulation of fat in hepatocytes in the absence of hepatocyte inflammation) ${ }^{7,8}$ to non-alcoholic steatohepatitis (NASH), defined histologically by the presence of hepatic steatosis and hepatocyte inflammation ${ }^{7,8-10}$ with varying levels of fibrosis, that can progress to cirrhosis, and complications such as portal hypertension, liver failure, and hepatocellular carcinoma (HCC). ${ }^{11}$ Liver biopsy is currently the standard for the diagnosis of NASH and assessment of fibrosis ${ }^{8,12}$ however, it is unappealing owing to several limitations, including pain, expense, and inaccuracy due to sampling errors. ${ }^{8,13}$

In this article, we present an algorithm for screening, risk stratification, and management of NAFLD patients in the primary care setting, based on expert opinion and consensus. The objectives of this algorithm are to help primary care providers (PCPs) identify patients at risk for NAFLD and recognize those who will benefit from specialist referral.

\section{Material and methods}

All 11 authors participated in a consensus meeting in December 2019 to develop a best-practices algorithm to identify, stratify, and manage NAFLD. All authors have expertise in evaluating and 
treating liver diseases, including NAFLD and NASH, and are advisors to NASHNET, a global Centers of Excellence Network committed to NASH care delivery innovation. ${ }^{14}$ Authors developed the preliminary content for the various sections, which was presented to the whole group for discussion and review. Through collaborative decision making, a consensus was reached on the algorithm, and recommendations are presented in this article.

\section{Results}

\section{Algorithm for screening, risk stratification, and management of NAFLD}

Screening

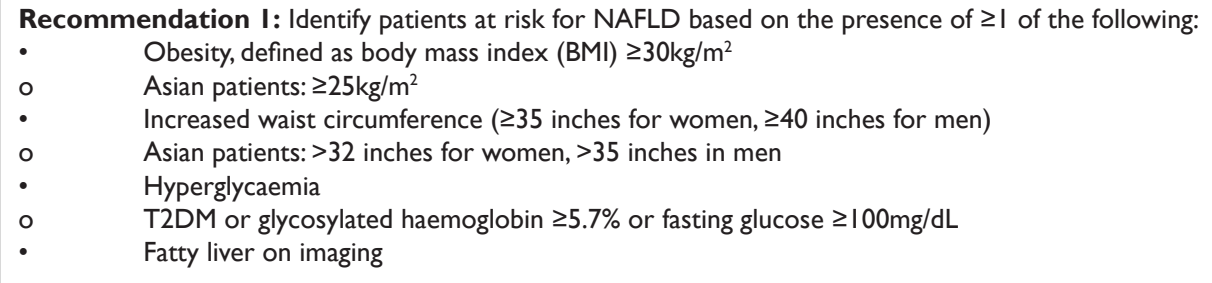

NAFLD is under-diagnosed and under-reported in primary care. ${ }^{15}$ Obesity and T2DM are leading risk factors for NAFLD (Table 1)., ${ }^{9,16}$ NAFLD, obesity, and T2DM are all independent risk factors for HCC. ${ }^{17-20}$ A systematic review and meta-analysis of 49,419 individuals with T2DM reported NAFLD in $56 \%$ of patients in the USA. ${ }^{2}$ The prevalence of NAFLD in obese patients undergoing bariatric surgery may be as high as $91 \%{ }^{21}$

Table I Definitions of metabolic syndrome $e^{84,85}$

\begin{tabular}{|c|c|c|}
\hline & NCEP ATP III (2004) & IDF (2005) \\
\hline Definition of metabolic syndrome & $\begin{array}{l}\text { Presence of at least three of the five risk factors } \\
\text { listed below }\end{array}$ & $\begin{array}{l}\text { Central obesity plus any two of the other four risk factors } \\
\text { listed below }\end{array}$ \\
\hline \multirow[t]{2}{*}{ Risk factors } & Defining level & Defining level \\
\hline & & $\begin{array}{l}\text { BMI }>30 \mathrm{~kg} / \mathrm{m}^{2} \text { or ethnicity-specific waist circumference } \\
\text { E Europid (European and North American), East- } \\
\text { ern Mediterranean, and Middle Eastern (Arab), sub-Saharan } \\
\text { African }\end{array}$ \\
\hline \multirow{6}{*}{ Central obesity } & Waist circumference & $\square \quad$ Men: $\geq 94 \mathrm{~cm}(\geq 37$ in $)$ \\
\hline & $\circ \quad$ Men: $>102 \mathrm{~cm}(>40 \mathrm{in})$ & $\square \quad$ Women: $\geq 80 \mathrm{~cm}(\geq 3 \mathrm{l}$ in $)$ \\
\hline & o Women: $>88 \mathrm{~cm}$ (>35 in) & - Ethnic South and Central American, South Asian, \\
\hline & & Chinese, Japanese \\
\hline & & $\square \quad$ Men: $\geq 90 \mathrm{~cm}(\geq 35$ in $)$ \\
\hline & & Women: $\geq 80 \mathrm{~cm}(\geq 31 \mathrm{in})$ \\
\hline Raised blood pressure & $\geq 130 / \geq 85 \mathrm{~mm} \mathrm{Hg}$ & $\begin{array}{l}\text { Systolic } \geq 130 \mathrm{~mm} \mathrm{Hg} \text { or diastolic } \geq 85 \mathrm{~mm} \mathrm{Hg} \\
\text { or treatment of previously diagnosed hypertension }\end{array}$ \\
\hline \multirow{2}{*}{ Raised fasting plasma glucose } & $\geq 110 \mathrm{mg} / \mathrm{dL}^{\mathrm{a}}$ & $\geq 100 \mathrm{mg} / \mathrm{dL}$ \\
\hline & $\geq 110 \mathrm{mg} / \mathrm{dL}^{\mathrm{d}}$ & or previously diagnosed T2DM \\
\hline \multirow{2}{*}{ Raised triglycerides } & $>150$ mald & $\geq 150 \mathrm{mg} / \mathrm{dL}$ \\
\hline & $\geq 150 \mathrm{mg} / \mathrm{dL}$ & or specific treatment for this lipid abnormality \\
\hline Reduced HDL cholesterol & $\begin{array}{l}\text { Men: }<40 \mathrm{mg} / \mathrm{dL} \\
\text { Women: }<50 \mathrm{mg} / \mathrm{dL}\end{array}$ & $\begin{array}{l}\text { Men: }<40 \mathrm{mg} / \mathrm{dL} \\
\text { Women: }<50 \mathrm{mg} / \mathrm{dL} \\
\text { or specific treatment for this lipid abnormality }\end{array}$ \\
\hline
\end{tabular}

BMI, body mass index; HDL, high-density lipoprotein; IDF, International Diabetes Federation; NCEP ATP III, National Cholesterol Education Program Adult Treatment Panel III report;T2DM, type 2 diabetes mellitus

${ }^{a}$ The American Diabetes Association has established a cut point of $\geq 100 \mathrm{mg} / \mathrm{dL}$, above which persons have either prediabetes (impaired fasting glucose) or diabetes 
There is a difference in opinion in who should be screened for NAFLD by multiple international guidelines. The European Association for the Study of the Liver (EASL), the European Association for the Study of Diabetes (EASD), and the European Association for the Study of Obesity (EASO) have jointly recommended that patients with obesity or metabolic syndrome should be screened routinely for NAFLD using liver enzymes and/or ultrasound.$^{22}$ The American Diabetes Association (ADA) recommends that patients with $\mathrm{T} 2 \mathrm{DM}$ or prediabetes and alanine aminotransferase. ALT) or fatty liver on ultrasound should be evaluated for presence of NASH and liver fibrosis. ${ }^{23}$ The American Association for the Study of Liver Diseases (AASLD) recommend screening for NAFLD in those with elevated aminotransferases and hepatic steatosis but no concrete recommendations are made for those with obesity or T2DM. ${ }^{8,24-26}$

We recommend that PCPs consider fatty liver in at-risk patients with three questions:

1. Does the patient have risk factors for NAFLD (see recommendation 1)?

2. If the answer is "yes", does the patient have evidence of NAFLD?

3. If the answer is "yes", does the patient have evidence of significant fibrosis by non-invasive tests?

Our algorithm for screening, risk stratification, and management of NAFLD in the primary care setting is presented in Figure 1.
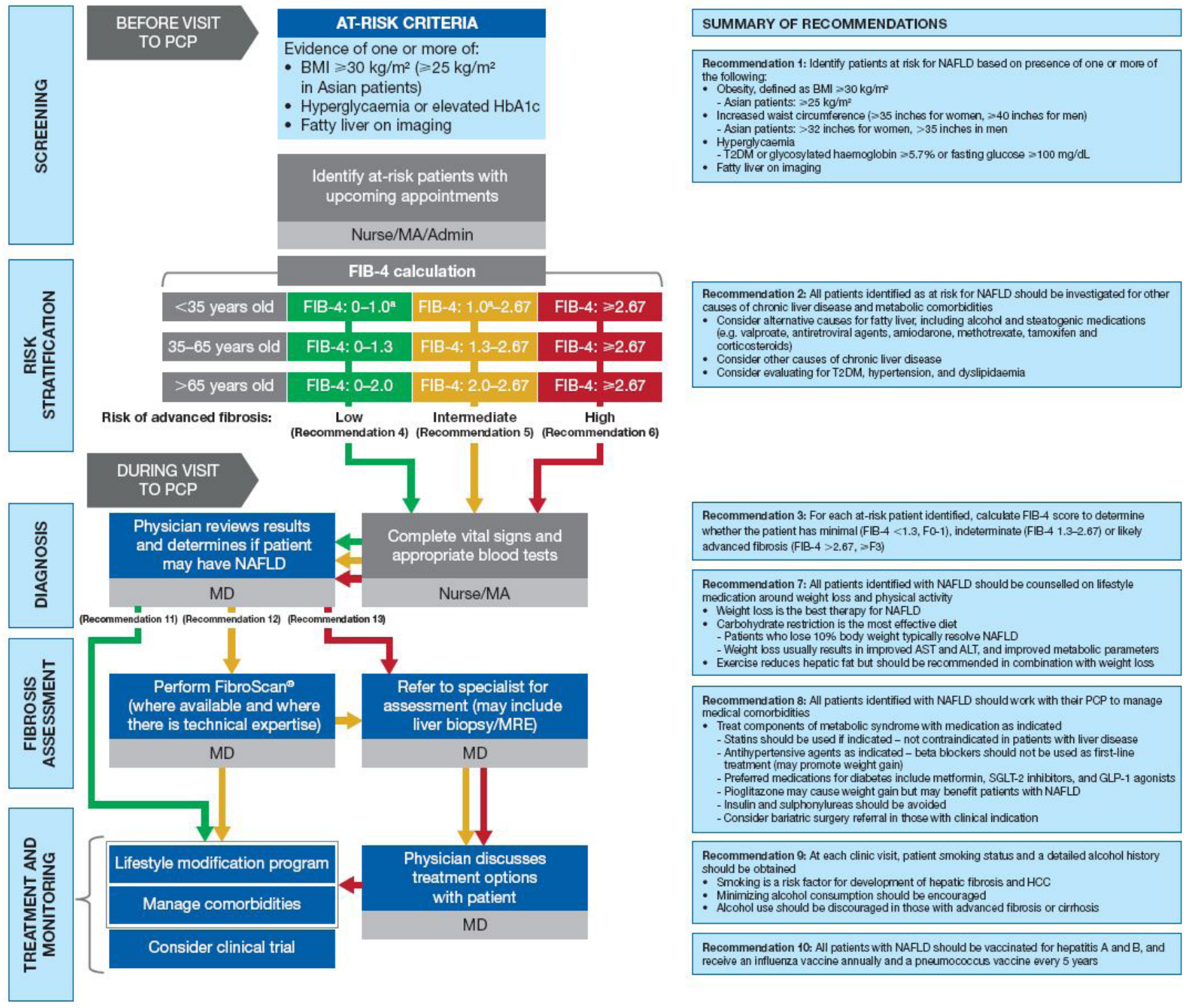

\begin{tabular}{|c|}
\hline SUMMARY OF RECOMMENDATIONS \\
\hline $\begin{array}{l}\text { Recommendation 1: Identify patients at risk for NAFLD based on presence of one } \alpha \text { more of } \\
\text { the following } \\
\text { Obesity, defined as BMl }>30 \mathrm{~kg} / \mathrm{m}^{2} \\
\text { - Isian patients: }>25 \mathrm{~kg} / \mathrm{m}^{2} \\
\text { - Increased waist circumference ( }>35 \text { inches for women, }>40 \text { inches for men) } \\
\text { - Asian patients: }>32 \text { inches for women, }>35 \text { inches in men } \\
\text { - Hyperglycaemia } \\
\text { - T2DM or glycosylated haemoglobin }>5.7 \% \text { or fasting gluccose }>100 \mathrm{mg} / \mathrm{dL} \\
\text { - Fatty liver on imaging }\end{array}$ \\
\hline
\end{tabular}

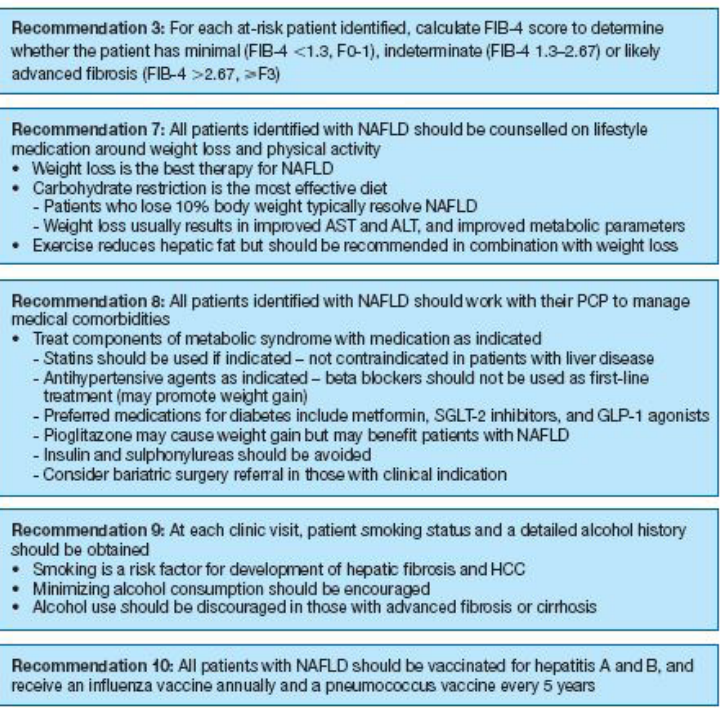

Figure I Algorithm for screening, risk stratification, and management of non-alcoholic fatty liver disease (NAFLD) in primary care.

Admin, administrative staff; ALT, alanine aminotransferase; AST, aspartate transaminase; BMI, body mass index; FIB-4, fibrosis-4 index; GLP-I, glucagon-like peptide-I; HCC, hepatocellular carcinoma; MA, medical assistant; MRE, magnetic resonance elastography; NAFLD, non-alcoholic fatty liver disease; PCP, primary care provider; SGLT-2, sodium-glucose co-transporter-2;T2DM, type 2 diabetes mellitus.

${ }^{2}$ Expert opinion - cutoff of 1.0 in individuals $<35$ years old not yet validated by clinical data. 


\section{Diagnosis}

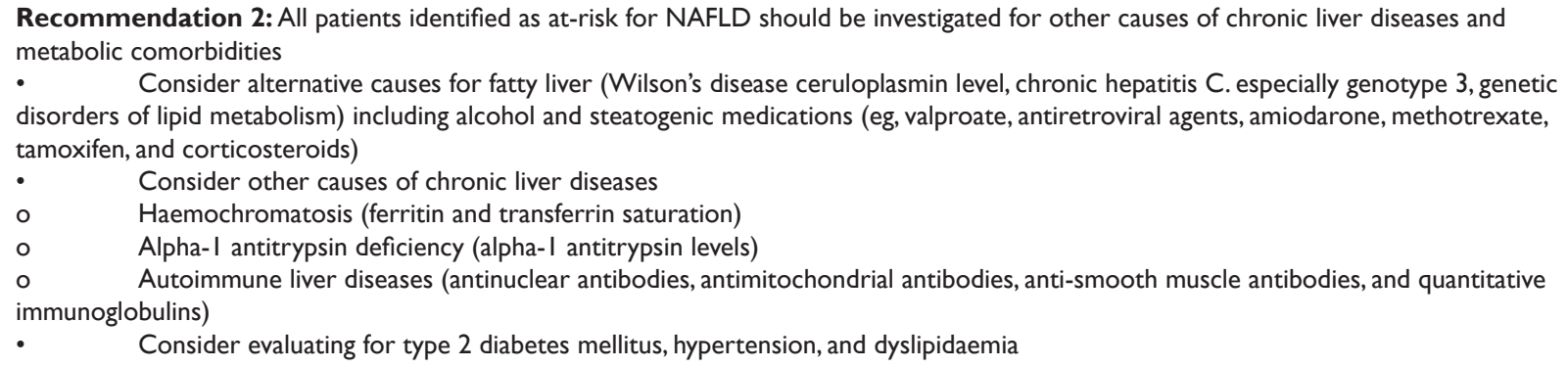

All patients identified as at-risk for NAFLD should have anthropometric measurements (height and weight to calculate BMI, a surrogate marker for obesity) vital signs, and laboratory tests performed (Table 2)..$^{8,27-36}$ Vital signs relevant to NAFLD include elevated blood pressure, indicative of essential hypertension, and increased waist circumference.

Table 2 Routine blood tests, with rationale

\begin{tabular}{|c|c|}
\hline Test & Rationale; normal values ${ }^{a}$ \\
\hline \multicolumn{2}{|l|}{ Liver panel } \\
\hline ALT & $\begin{array}{l}\text { Elevated ALT may indicate hepatocyte injury }{ }^{27 b} \\
\text { Normal range } \mathrm{e}^{28}: \leq 35 \mathrm{U} / \mathrm{L} \text { for men and } \leq 25 \mathrm{U} / \mathrm{L} \text { for women }\end{array}$ \\
\hline Albumin & $\begin{array}{l}\text { Albumin is produced only in the liver, so low albumin may indicate impaired synthetic liver function }{ }^{27} \\
\text { Normal range } \mathrm{e}^{29}: 3.5-5.4 \mathrm{~g} / \mathrm{dL}\end{array}$ \\
\hline Bilirubin (direct and total) & $\begin{array}{l}\text { High direct bilirubin may indicate liver dysfunction }{ }^{27} \\
\text { Direct bilirubin normal range } \\
\text { Total bilirubin normal range } \mathrm{e}^{29}: 0.3-1.2 \mathrm{mg} / \mathrm{dL}\end{array}$ \\
\hline GGT & $\begin{array}{l}\text { Elevated GGT is a predictor of liver mortality }{ }^{27} \\
\text { Normal range }{ }^{29}: 8-78 \mathrm{U} / \mathrm{L}\end{array}$ \\
\hline \multicolumn{2}{|l|}{ BMP } \\
\hline Serum creatinine & $\begin{array}{l}\text { Renal dysfunction is common in patients with cirrhosis, but also seen in patients with metabolic } \\
\text { syndrome without NAFLD } \\
\text { Normal range } \mathrm{e}^{29}: 0.7-1.3 \mathrm{mg} / \mathrm{dL}\end{array}$ \\
\hline Serum sodium & $\begin{array}{l}\text { Hyponatraemia has prognostic significance in patients with cirrhosis }{ }^{31} \\
\text { Normal range }{ }^{29}: 136-145 \mathrm{mEq} / \mathrm{L}\end{array}$ \\
\hline INR & $\begin{array}{l}\text { Important indicator of liver function as clotting factors are made by the liver; significant liver injury may } \\
\text { result in coagulopathy }{ }^{27} \\
\text { Normal range }^{32}: 0.8-1.1\end{array}$ \\
\hline \multicolumn{2}{|l|}{ CBC } \\
\hline Platelet count & $\begin{array}{l}\text { Low platelet count may indicate portal hypertension, which occurs in advanced fibrosis }{ }^{31} \\
\text { Normal rang }{ }^{33}: 150-400 \times 10^{9} / \mathrm{L}\end{array}$ \\
\hline $\mathrm{HbAlc}$ & $\begin{array}{l}\text { Test for T2DM (component of metabolic syndrome); routine health parameter [8] } \\
\text { Normal }{ }^{31}:<5.7 \% \\
\text { Prediabetes }^{34}: 5.7-6.4 \%\end{array}$ \\
\hline TSH & $\begin{array}{l}\text { Test for hypothyroidism; routine health parameter }{ }^{8} \text {; low free T4 level is a risk factor for NAFLD } \\
\text { Normal TSH range }{ }^{29}: 0.5-5.0 \mathrm{mlU} / \mathrm{L}\end{array}$ \\
\hline Lipid panel & Component of metabolic syndrome; routine health parameter ${ }^{8}$ \\
\hline $\begin{array}{l}\mathrm{HBsAg} \text {, anti-HBc, IgG (not IgM), anti- } \\
\mathrm{HBs} \text {, and anti-HCV with reflex to PCR }\end{array}$ & To rule out viral hepatitis ${ }^{27}$ \\
\hline
\end{tabular}

ALT, alanine aminotransferase; anti-HBc, total hepatitis B core antibody; anti-HBs, hepatitis B surface antibody; BMP, basic metabolic panel; CBC, complete blood count; GGT, gamma-glutamyltransferase; HbA Ic, glycated haemoglobin A I c; HBsAg, hepatitis B surface antigen; HCV, hepatitis C virus; Ig, immunoglobulin; INR, international normalized ratio; NAFLD, non-alcoholic fatty liver disease; PCR, polymerase chain reaction;T2DM, type 2 diabetes mellitus;TSH, thyroid-stimulating hormone

${ }^{a}$ Normal values vary between laboratories and may also differ between men and women and between adults and children. ${ }^{\mathrm{b}} \mathrm{ALT}$ may be within normal limits in patients with NAFLD ${ }^{36}$ 
There is no specific sign or symptom for NAFLD. In addition, there is no diagnostic laboratory test to confirm diagnosis. ALT can be normal in up to $50 \%$ of persons with NAFLD. ${ }^{37}$ While elevated ALT and aspartate transaminase (AST) levels indicate the presence of liver injury and NASH they do not always correlate with the severity of liver damage. ${ }^{27,38,39}$ An upper limit of normal for ALT of $35 \mathrm{U} / \mathrm{L}$ for men and $25 \mathrm{U} / \mathrm{L}$ for women is recommended to guide management decisions. ${ }^{28}$ Low platelet count may indicate presence of portal hypertension. Albumin, total bilirubin, and international normalized ratio are indicators of liver synthetic function. Patients with cirrhosis frequently have more than one abnormality on routine blood tests. ${ }^{27}$

When assessing for NAFLD, exclude other causes of hepatic steatosis or chronic liver disease. Alcohol-related liver disease is the other common cause of fatty liver disease. Patients should be asked directly about their alcohol intake, for example, with the Alcohol Use Disorders Identification Test (AUDIT).$^{40}$ As patients may underreport their alcohol consumption, assessment using biomarkers of alcohol use, such as ethyl glucuronide or phosphatidyl ethanol, may be useful. ${ }^{41}$ An AST level greater than ALT may be more indicative of alcoholic versus non-alcoholic steatohepatitis, except in patients with advanced liver disease. Although NAFLD indicates the lack of evidence for ongoing or recent consumption of significant amounts of alcohol, the precise definition of significant alcohol consumption in patients with suspected NAFLD is uncertain. ${ }^{8}$ Other causes of hepatic steatosis should be considered (Recommendation 2$)^{8,13,27,42}$ and risk factors of metabolic syndrome should also be investigated (Table 3).

Table 3 Sensitivity and specificity of widely available non-invasive tests for advanced fibrosis (stage 3 or higher) in NAFLD ${ }^{43}$

\begin{tabular}{|c|c|c|c|c|}
\hline Test & Components & Cutoffs & Sensitivity & Specificity \\
\hline FIB-4 score & Age,ALT,AST, platelet count & $\begin{array}{l}<1.3 \\
\geq 2.67\end{array}$ & $\begin{array}{l}0.82 \\
0.36\end{array}$ & $\begin{array}{l}0.57 \\
0.93\end{array}$ \\
\hline NAFLD fibrosis score & $\begin{array}{l}\text { Age,ALT,AST, platelet count, albumin, BMI, } \\
\text { presence of impaired fasting glucose or T2DM }\end{array}$ & $\begin{array}{l}<-1.455 \\
\geq 0.676\end{array}$ & $\begin{array}{l}0.89 \\
0.38\end{array}$ & $\begin{array}{l}0.37 \\
0.89\end{array}$ \\
\hline FibroScan ${ }^{\circledR}$ LSM & Elastographic method & $\begin{array}{l}<9.9 \mathrm{kPa} \\
\geq 11.4 \mathrm{kPa}\end{array}$ & $\begin{array}{l}0.83 \\
0.75\end{array}$ & $\begin{array}{l}0.61 \\
0.71\end{array}$ \\
\hline
\end{tabular}

ALT, alanine aminotransferase; AST, aspartate aminotransferase; BMI, body mass index; FIB-4, fibrosis-4 index; LSM, liver stiffness measurement; NAFLD, nonalcoholic fatty liver disease;T2DM, type 2 diabetes mellitus

\section{Risk stratification and fibrosis assessment}

Recommendation 3: For each at-risk patient identified, calculate fibrosis-4 index (FIB-4) score to determine whether the patient has minimal (FIB-4: <I.3, F0-I), indeterminate (FIB-4: I.3-2.67), or likely advanced fibrosis (FIB-4: $>2.67, \geq F 3$ )

Recommendation 4: Patients with FIB-4 <I.3 have minimal fibrosis. These patients can be managed by their PCP

Recommendation 5: Patients with FIB-4 I.3-2.67 have an indeterminate fibrosis score and should have a second non-invasive test such as Fibro Sure or ELF (serology-based tests) or liver stiffness (imaging based elastography)

Recommendation 6: Patients with FIB-4 $>2.67$ have a $97 \%$ likelihood of advanced fibrosis and should be referred to a hepatologist

Once an at-risk patient has been identified, the patient should be stratified into low (fibrosis stage $0-1$ ), indeterminate (fibrosis stage 2), or advanced fibrosis (fibrosis stage 3 and higher) using non-invasive tests (NITs). Several NITs have been tested and validated to detect fibrosis stage in NAFLD (Table 3 ). ${ }^{43}$

A recent meta-analysis (64 studies, 13,046 NAFLD patients) compared a panel of tests (BARD.BMI, AST/ALT ratio, diabetes, APRI.AST to platelet ratio index, FIB-4.fibrosis-4 index, and NFS. NAFLD fibrosis score) for diagnosing advanced fibrosis with reported area under the receiver operating characteristic curve of $0.76,0.77$, 0.84 , and 0.84 , respectively. ${ }^{44}$ Among the four serum-based NITs, FIB-4, and NFS performed best, with negative predictive values $>90 \% .{ }^{44}$ FIB-4 and NFS have strong negative predictive values and predict a better long-term outcome. ${ }^{45,46}$

Here we propose the application of FIB-4 for initial risk stratification. It is a simple, inexpensive NIT and includes variables (age, AST, ALT, and platelet count) that are typically obtained during PCP clinic visits. ${ }^{47,48}$ FIB-4 is an effective tool to rule out advanced fibrosis (Table 3) and possibly avoid unnecessary referrals to specialist care ${ }^{49,50}$ A FIB- 4 cutoff of $<1.3$ provides a sensitivity of 0.82 and a specificity of 0.57 for excluding advanced fibrosis and a cutoff of $\geq 2.67$ provides a sensitivity of 0.36 and a specificity of 0.93 for detecting advanced fibrosis. ${ }^{43}$ As age can influence the accuracy of the degree of fibrosis determined by FIB-4, we propose a different cut off for minimal fibrosis in patients aged $<35$ years or $>65$ years (Table 3)..$^{51}$

Patients with an indeterminate NIT should have a second test, either serology or imaging based. ${ }^{48}$ (Figure 1). Choice of test should be determined by availability and if unclear, guidance can be obtained from a hepatologist. A step-wise approach has been outlined in primary care settings, to decrease the large influx of NAFLD referrals to specialty care and utilize limited specialty resources for those at risk of advanced disease. ${ }^{52}$

The accuracy of commonly used serology-based NITs has been described above and in Table 2. Imaging-based technologies have gained popularity, most notably FibroScan ${ }^{\circledR}$, a non-invasive, quick, reproducible, point-of-care test, with results that can be shared immediately with the patient and providers..$^{53,54}$ In addition to providing information about liver stiffness, degree of hepatic steatosis can be estimated with the controlled attenuation parameter feature. ${ }^{55}$ Vibration-controlled transient elastography (VCTE) is highly sensitive and provides a negative predictive value of $99 \%$ for ruling out stage 
3-4 fibrosis (Table 3). ${ }^{43,56,57}$ Factors to consider include asking the patient to fast for 3-4 hours before examination and awareness of patient characteristics that can overestimate the degree of liver stiffness, such as body habitus (accounting for $5 \%$ failure rate).

\section{Treatment and monitoring}

Recommendation 7: All patients identified with NAFLD should be counselled on lifestyle medication around weight loss and physical activity

- Weight loss is the best therapy for NAFLD

- $\quad$ Carbohydrate restriction is the most effective diet

- Patients who lose $10 \%$ body weight typically resolve NAFLD

- Weight loss usually results in improved AST and ALT and improved metabolic parameters

- $\quad$ Exercise reduces hepatic fat but should be recommended in combination with weight loss

Recommendation 8: All patients identified with NAFLD should work with their PCP to manage medical comorbidities

- $\quad$ Treat components of metabolic syndrome with medication as indicated

- Statins should be used if indicated - not contraindicated in patients with liver disease

- Antihypertensive agents as indicated - beta-blockers should not be used as first-line treatment (may promote weight gain)

- Preferred medications for diabetes include metformin, sodium-glucose co-transporter-2 inhibitors (SGLT2i), and glucagon-like peptide-I (GLP-I) agonists

○ Pioglitazone may cause weight gain but may benefit patients with NAFLD

- Insulin and sulphonylureas should be avoided

- Consider bariatric surgery referral in those with clinical indication

Recommendation 9: At each clinic visit, patient smoking status and detailed alcohol history should be obtained

- Smoking is a risk factor for the development of hepatic fibrosis and HCC

- $\quad$ Advice on keeping alcohol consumption to a minimum should be encouraged

- Alcohol use should be discouraged in those with advanced fibrosis or cirrhosis

Recommendation I0: All patients with NAFLD should be vaccinated for hepatitis A and B virus, receive an annual influenza virus vaccine, and a pneumococcal vaccine every 5 years

Recommendation I I: Patients with no evidence of significant fibrosis (fibrosis-4 index. ${ }^{\text {IIB-4 }}<$ I.3) should work with their PCP to manage medical comorbidities

Recommendation I2: Patients with evidence of significant fibrosis (FIB-4 $\geq 1.3$ ) should be comanaged by their PCP and referred to a hepatologist

Recommendation 13: Patients with advanced fibrosis (FIB-4 $>2.67$ ) should be considered for screening for HCC every 6 months

\section{Discussion}

Lifestyle interventions are key in the clinical management of all spectrums of NAFLD. ${ }^{8,22,58}$ Weight loss is considered the cornerstone of treatment and shown to improve steatosis, liver injury, and fibrosis. ${ }^{59}$ Weight loss goals need to be measurable, reasonable, and tailored to each individual patient. ${ }^{60}$ The approach to dietary changes should incorporate MyPlate ${ }^{61}$ and individualized modification of current diet versus adoption of unsustainable, radical diets. The intake of fructose (particularly sugar-sweetened beverages) should be strongly discouraged. ${ }^{58} \mathrm{~A}$ meta-analysis of 12 studies involving 35,705 participants found that consumption of sugar-sweetened beverages increased the relative risk of NAFLD by $39 \% .{ }^{62}$ While there is no specific type of exercise to be most impactful in NAFLD,${ }^{58}$ any form of movement or fitness should be encouraged. Dietary advice, ${ }^{63}$ fitness, and weight loss goals should be included in the treatment plan.

Other lifestyle changes that should be addressed at every visit are inquiry into smoking and counselling on smoking cessation; and a detailed history of alcohol use and methods to decrease alcohol intake. Smoking is a risk factor for the development of hepatic fibrosis and HCC. ${ }^{64,65}$ In a retrospective analysis that assessed risk factors associated with long-term outcomes in 619 patients with NAFLD, in addition to fibrosis stage, smoking was associated with a 2- to 3-fold increased risk of overall and liver-related mortality. ${ }^{10}$ Heavy alcohol use is especially detrimental to patients with NAFLD. Observational studies demonstrated an increased risk of hepatic inflammation, cirrhosis, and HCC in obese and diabetic individuals who consumed $>2$ alcoholic drinks per day ${ }^{66-68}$ Any quantity of alcohol use in persons with NASH-related cirrhosis increases the risk of HCC by fourfold (hazard ratio 3.8, 95\% CI 1.6-8.9, $P<0.01$ ) and the risk was not modified by volume of alcohol use or former drinking. ${ }^{69} \mathrm{We}$ recommend complete abstinence in patients with advanced fibrosis and cirrhosis.

NAFLD is part of the metabolic syndrome spectrum and so managing metabolic comorbidities is imperative. PCPs should consider managing patients with NAFLD as part of a multidisciplinary team that includes dieticians, psychologists, community healthcare workers, and exercise physiologists. ${ }^{60}$

Metformin is not recommended for NAFLD or NASH but should be considered as first-line pharmacologic therapy for those with NAFLD and T2DM. Metformin promotes weight loss, decreases body fat, and improves hepatic insulin sensitivity. ${ }^{70}$ We recommend against diabetes medications more prone to increasing weight. In patients with T2DM and NASH, GLP-1 receptor agonists or SGLT-2is can be considered as second-line agents. ${ }^{71}$ Both agents have shown secondary benefits on weight loss, glycemic control, and improvement in NASH. ${ }^{72-76}$ 
Dyslipidaemia in patients with NAFLD and NASH should be treated. ${ }^{8}$ Statins can be protective against $\mathrm{HCC}$ and liver fibrosis and they reduce cardiovascular disease morbidity and mortality. ${ }^{77,78}$ Statins can be well tolerated and efficacious in patients with compensated NASH cirrhosis, but should be avoided in patients with decompensated cirrhosis. ${ }^{8}$ Renin-angiotensin inhibitors may have antifibrotic properties and hence can be prescribed for hypertension in NAFLD and NASH patients. ${ }^{79}$

Bariatric surgery should be considered as a treatment option in patients with NAFLD who meet criteria. ${ }^{8}$ In a systematic review and meta-analysis (including 3093 patients with NAFLD), bariatric surgery resulted in resolution of steatosis in $66 \%$ of patients and resolution of fibrosis in $40 \% .^{80,81}$

All patients with NAFLD need longitudinal follow up. Those identified with minimal fibrosis (FIB-4 $<1.3$, F0-1) can be followed by PCPs to manage metabolic comorbidities, and bi-annual blood work including blood count, liver enzymes, $\mathrm{HbAlc}$, and lipids to monitor and detect metabolic diseases. PCPs should calculate hepatic and cardiovascular risks every year and refer to a hepatologist and/ or cardiologist if indicated. Patients with intermediate or advanced fibrosis (FIB- $4 \geq 1.3$ and $\geq 2$, respectively) should also be followed by primary care in consultation with a hepatologist.

All patients with a diagnosis of chronic liver disease such as NAFLD should be vaccinated for hepatitis A and B, if not already immune. We also recommend annual influenza virus vaccination and a pneumococcal vaccination every 5years. Patients with stage 3 fibrosis or higher should be considered for screening for HCC every 6 months, ${ }^{82}$ because as many as $25 \%$ of these patients can develop HCC in the absence of cirrhosis. ${ }^{83}$

\section{Conclusions}

Like obesity and T2DM, NAFLD has become an epidemic. While liver biopsy is the mainstay for diagnosing NASH and advanced fibrosis, NITs are a cost-effective method of stratifying patients in low- and high-risk groups. This algorithm encourages the PCP to recognize the potential for end-organ damage and intervene in time to improve patient health and longevity. The stratification scheme encourages maximum use of the PCP's time and skills and improves the utilization of specialists. PCPs are overburdened, so the addition of ancillary staff to assist with dietary and lifestyle changes are essential to the effective management of these patients.

\section{Acknowledgments}

NASHNET contracted Caudex, New York, NY, USA for professional medical writing support. Writing and editorial support, respectively, were provided by Simon Wigfield and Reza Sayeed of Caudex, Oxford, UK and Stephanie Wolfe of Caudex, New York, NY, USA.

\section{Conflicts of interest}

All authors declare there are no conflicts of interest towards this manuscript.

\section{Funding}

The algorithm-development meeting and manuscript development, including professional medical writing and editorial support, were internally funded by NASHNET.

\section{References}

1. Setiawan VW, Stram DO, Porcel J, et al. Prevalence of chronic liver disease and cirrhosis by underlying cause in understudied ethnic groups: the Multiethnic Cohort. Hepatology. 2016;64:1969-1977.

2. Younossi ZM, Golabi P, de Avila L, et al. The global epidemiology of NAFLD and NASH in patients with type 2 diabetes: a systematic review and meta-analysis. J Hepatol. 2019;71:793-801.

3. Centers for Disease Control and Prevention(CDC). Adult obesity facts. USA: Centers for Disease Control and Prevention; 2020.

4. Mittal S, El-Serag HB, Sada YH, et al. Hepatocellular carcinoma in the absence of cirrhosis in United States veterans is associated with nonalcoholic fatty liver disease. Clin Gastroenterol Hepatol. 2016;14:124-131.e1.

5. Ismaiel A, Dumitraşcu DL. Cardiovascular risk in fatty liver disease: the liver-heart axis-literature review. Front Med (Lausanne). 2019;6:202.

6. Desai A, Sandhu S, Lai JP, et al. Hepatocellular carcinoma in non-cirrhotic liver: A comprehensive review. World J Hepatol 2019; 11(1):1-18.

7. Alvarez CS, Graubard BI, Thistle JE, et al. Attributable fractions of NAFLD for mortality in the United States: results from NHANES III with 27 years of follow-up. Hepatology. 2020;72(2):430-440.

8. Chalasani N, Younossi Z, Lavine JE, et al. The diagnosis and management of nonalcoholic fatty liver disease: practice guidance from the American Association for the Study of Liver Diseases. Hepatology. 2018;67(1):328357.

9. Bellentani S. The epidemiology of non-alcoholic fatty liver disease. Liver Int. 2017; 37 Suppl 1:81-84.

10. Angulo P, Kleiner DE, Dam-Larsen S, et al. Liver fibrosis, but no other histologic features, is associated with long-term outcomes of patients with nonalcoholic fatty liver disease. Gastroenterology. 2015;149((2):389397.e10.

11. Calzadilla Bertot L, Adams LA. The natural course of non-alcoholic fatty liver disease. Int J Mol Sci. 2016;17(5):774.

12. Sanyal AJ. Putting non-alcoholic fatty liver disease on the radar for primary care physicians: how well are we doing? BMC Med. 2018;16(1):148.

13. Tapper EB, Lok AS. Use of liver imaging and biopsy in clinical practice. N Engl J Med. 2017;377(23):756-768.

14. NASHNET. Who we are. 2020.

15. Alexander M, Loomis AK, Fairburn-Beech J, et al. Real-world data reveal a diagnostic gap in non-alcoholic fatty liver disease. $B M C \mathrm{Med}$. 2018;16(1):130.

16. Kitade H, Chen G, Ni Y, Ota T. Nonalcoholic fatty liver disease and insulin resistance: new insights and potential new treatments. Nutrients. 2017;9(4):387.

17. Younossi Z, Stepanova M, Ong JP, et al. Nonalcoholic steatohepatitis is the fastest growing cause of hepatocellular carcinoma in liver transplant candidates. Clin Gastroenterol Hepatol. 2019;17(4):748-755.e3.

18. Li X, Wang X, Gao P. Diabetes mellitus and risk of hepatocellular carcinoma. Biomed Res Int. 2017;2017:5202684.

19. Calle EE, Rodriguez C, Walker-Thurmond K, et al. Overweight, obesity, and mortality from cancer in a prospectively studied cohort of U.S. adults. N Engl J Med. 2003;348(17):1625-1638.

20. Mantovani A, Targher G. Type 2 diabetes mellitus and risk of hepatocellular carcinoma: spotlight on nonalcoholic fatty liver disease. Ann Transl Med. 2017;5:270. 
21. Machado M, Marques-Vidal P, Cortez-Pinto H. Hepatic histology in obese patients undergoing bariatric surgery. J Hepatol. 2006;45:600-606.

22. European Association for the Study of the Liver, European Association for the Study of Diabetes, European Association for the Study of Obesity. EASL-EASD-EASO clinical practice guidelines for the management of non-alcoholic fatty liver disease. J Hepatol. 2016;64(6):1388-1402.

23. American Diabetes Association. Comprehensive medical evaluation and assessment of comorbidities: standards of medical care in diabetes - 2020 . Diabetes Care. 2020;43(Suppl 1):S37-S47.

24. Sotoudehmanesh R, Sotoudeh M, Ali-Asgari A, et al. Silent liver diseases in autopsies from forensic medicine of Tehran. Arch Iran Med. 2006;9(4):324-328.

25. Zois CD, Baltayiannis GH, Bekiari A, et al. Steatosis and steatohepatitis in postmortem material from Northwestern Greece. World $J$ Gastroenterol. 2010;16(31):3944-3949.

26. Amarapurkar A, Ghansar T. Fatty liver: experience from western India. Ann Hepatol. 2007;6(1):37-40.

27. Newsome PN, Cramb R, Davison SM, et al. Guidelines on the management of abnormal liver blood tests. Gut. 2018;67(1):6-19.

28. Terrault NA, Lok ASF, McMahon BJ, et al. Update on prevention, diagnosis, and treatment of chronic hepatitis B: AASLD 2018 hepatitis B guidance. Hepatology. 2018;67(4):1560-1599.

29. MSD. Blood tests: normal values. 2018.

30. Nam GE, Hwang SY, Chung HS, et al. Implication of nonalcoholic fatty liver disease, metabolic syndrome, and subclinical inflammation on mild renal insufficiency. Int J Endocrinol. 2018;2018:1835486.

31. John S, Thuluvath PJ. Hyponatremia in cirrhosis: pathophysiology and management. World J Gastroenterol. 2015;21(11):3197-3205.

32. Tuazon SA. Prothrombin time. 2019.

33. Bonaccio M, Di Castelnuovo A, Costanzo S, et al. Age-sex-specific ranges of platelet count and all-cause mortality: prospective findings from the MOLI-SANI study. Blood. 2016;127(12):1614-1616.

34. American Diabetes Association. 2. Classification and diagnosis of diabetes: standards of medical care in diabetes - 2020. Diabetes Care. 2020;43():S14-S31.

35. Bano A, Chaker L, Plompen EP, et al. Thyroid function and the risk of nonalcoholic fatty liver disease: the Rotterdam Study. J Clin Endocrinol Metab. 2016;101(8):3204-3211.

36. Fracanzani AL, Valenti L, Bugianesi E, et al. Risk of severe liver disease in nonalcoholic fatty liver disease with normal aminotransferase levels: a role for insulin resistance and diabetes. Hepatology. 2008;48(3):792-798.

37. Sanyal D, Mukherjee P, Raychaudhuri M, et al. Profile of liver enzymes in non-alcoholic fatty liver disease in patients with impaired glucose tolerance and newly detected untreated type 2 diabetes. Indian $J$ Endocrinol Metab. 2015;19(5):597-601.

38. Ahmed Z, Ahmed U, Walayat S, et al. Liver function tests in identifying patients with liver disease. Clin Exp Gastroenterol. 2018;11:301-307.

39. Williams CD, Stengel J, Asike MI, et al. Prevalence of nonalcoholic fatty liver disease and nonalcoholic steatohepatitis among a largely middleaged population utilizing ultrasound and liver biopsy: a prospective study. Gastroenterology. 2011;140(1):124-131.

40. National Institute on Drug Abuse. Alcohol Use Disorders Identification Test (AUDIT). 2020

41. Allen JP, Wurst FM, Thon N, et al. Assessing the drinking status of liver transplant patients with alcoholic liver disease. Liver Transpl. 2013;19(4):369-376.
42. Roberts EA, Schilsky ML. Diagnosis and treatment of Wilson disease: an update. Hepatology. 2008;47(6):2089-2111.

43. Anstee QM, Lawitz EJ, Alkhouri N, et al. Noninvasive tests accurately identify advanced fibrosis due to NASH: baseline data from the STELLAR trials. Hepatology. 2019;70(5):1521-1530.

44. Xiao G, Zhu S, Xiao X, et al. Comparison of laboratory tests, ultrasound or magnetic resonance elastography to detect fibrosis in patients with nonalcoholic fatty liver disease: A meta-analysis. Hepatology. 2017;66(5):1486-1501

45. Hagström H, Nasr P, Ekstedt M, et al. Fibrosis stage but not NASH predicts mortality and time to development of severe liver disease in biopsy-proven NAFLD. J Hepatol. 2017;67(6):1265-1273.

46. Angulo P, Bugianesi E, Bjornsson ES, et al. Simple noninvasive systems predict long-term outcomes of patients with nonalcoholic fatty liver disease. Gastroenterology. 2013;145(4):782-789.e4.

47. Shah AG, Lydecker A, Murray $\mathrm{K}$, et al. Comparison of noninvasive markers of fibrosis in patients with nonalcoholic fatty liver disease. Clin Gastroenterol Hepatol. 2009;7(10):1104-1112.

48. Davyduke T, Tandon P, Al-Karaghouli M, et al. Impact of implementing a "FIB-4 first" strategy on a pathway for patients with NAFLD referred from primary care. Hepatol Commun. 2019;3(10):1322-1333.

49. Tsochatzis EA, Newsome PN. Non-alcoholic fatty liver disease and the interface between primary and secondary care. Lancet Gastroenterol Hepatol. 2018;3(7):509-517.

50. Srivastava A, Jong S, Gola A, et al. Cost-comparison analysis of FIB-4, ELF and fibroscan in community pathways for non-alcoholic fatty liver disease. BMC Gastroenterol. 2019;19(1):122.

51. McPherson S, Hardy T, Dufour JF, et al. Age as a confounding factor for the accurate non-invasive diagnosis of advanced NAFLD fibrosis. $\mathrm{Am} \mathrm{J}$ Gastroenterol. 2017;112(5):740-751.

52. Pandyarajan V, Gish RG, Alkhouri N, et al. Screening for nonalcoholic fatty liver disease in the primary care clinic. Gastroenterol Hepatol (N Y). 2019;15(7):357-365.

53. Drescher HK, Weiskirchen S, Weiskirchen R. Current status in testing for nonalcoholic fatty liver disease (NAFLD) and nonalcoholic steatohepatitis (NASH). Cells. 2019;8(8):845.

54. Vuppalanchi R, Siddiqui MS, Van Natta ML, et al. Performance characteristics of vibration-controlled transient elastography for evaluation of nonalcoholic fatty liver disease. Hepatology. 2018;67(1):134-144.

55. Pu K, Wang Y, Bai S, et al. Diagnostic accuracy of controlled attenuation parameter (CAP) as a non-invasive test for steatosis in suspected nonalcoholic fatty liver disease: a systematic review and meta-analysis. $B M C$ Gastroenterol. 2019;19(1):51.

56. Wong VW, Vergniol J, Wong GL, et al. Diagnosis of fibrosis and cirrhosis using liver stiffness measurement in nonalcoholic fatty liver disease. Hepatology. 2010;51(2):454-462.

57. Singh S, Allen AM, Wang Z, et al. Fibrosis progression in nonalcoholic fatty liver vs nonalcoholic steatohepatitis: a systematic review and meta-analysis of paired-biopsy studies. Clin Gastroenterol Hepatol. 2015;13:643-654.e1-9;quiz e39-e40.

58. Hallsworth K, Adams LA. Lifestyle modification in NAFLD/NASH: facts and figures. JHEP Reports. 2019;1(6):468-479.

59. Vilar-Gomez E, Martinez-Perez Y, Calzadilla-Bertot L, et al. Weight loss through lifestyle modification significantly reduces features of nonalcoholic steatohepatitis. Gastroenterology. 2015;149(2):367-78 e5; quiz e14-e15.

60. Romero-Gómez M, Zelber-Sagi S, Trenell M. Treatment of NAFLD with diet, physical activity and exercise. J Hepatol. 2017;67(4):829-846. 
61. United States Department of Agriculture. ChooseMyPlate. 2015.

62. Chen H, Wang J, Li Z, et al. Consumption of sugar-sweetened beverages has a dose-dependent effect on the risk of non-alcoholic fatty liver disease: an updated systematic review and dose-response meta-analysis. Int J Environ Res Public Health. 2019;16(12):2192.

63. Schwarz JM, Noworolski SM, Erkin-Cakmak A, et al. Effects of dietary fructose restriction on liver fat, de novo lipogenesis, and insulin kinetics in children with obesity. Gastroenterology. 2017;153(3):743-652.

64. Ou H, Fu Y, Liao W, et al. Association between smoking and liver fibrosis among patients with nonalcoholic fatty liver disease. Can J Gastroenterol Hepatol. 2019;2019:6028952.

65. Baecker A, Liu X, La Vecchia C, et al. Worldwide incidence of hepatocellular carcinoma cases attributable to major risk factors. Eur $J$ Cancer Prev. 2018;27(3):205-212.

66. Hassan MM, Hwang LY, Hatten CJ, et al. Risk factors for hepatocellular carcinoma: synergism of alcohol with viral hepatitis and diabetes mellitus. Hepatology. 2002;36(5):1206-1213.

67. Ruhl CE, Everhart JE. Joint effects of body weight and alcohol on elevated serum alanine aminotransferase in the United States population. Clin Gastroenterol Hepatol. 2005;3(12):1260-1268.

68. Naveau S, Giraud V, Borotto E, et al. Excess weight risk factor for alcoholic liver disease. Hepatology. 1997;25(1):108-111.

69. Ascha MS, Hanouneh IA, Lopez R, et al. The incidence and risk factors of hepatocellular carcinoma in patients with nonalcoholic steatohepatitis. Hepatology. 2010;51(6):1972-1978.

70. Dharmalingam M, Yamasandhi PG. Nonalcoholic fatty liver disease and type 2 diabetes mellitus. Indian J Endocrinol Metab. 2018;22(3):421-428.

71. Shimizu M, Suzuki K, Kato K, et al. Evaluation of the effects of dapagliflozin, a sodium-glucose co-transporter-2 inhibitor, on hepatic steatosis and fibrosis using transient elastography in patients with type 2 diabetes and non-alcoholic fatty liver disease. Diabetes Obes Metab. 2019;21(2):285-292.

72. Newsome PN, Buchholtz K, Cusi K, et al. A placebo-controlled trial of subcutaneous semaglutide in nonalcoholic steatohepatitis. $N$ Engl J Med. 2021;384(12):1113-1124.

73. Armstrong MJ, Gaunt P, Aithal GP, et al. Liraglutide safety and efficacy in patients with non-alcoholic steatohepatitis (LEAN): a multicentre, double-blind, randomised, placebo-controlled phase 2 study. Lancet. 2016;387(10019):679-690.
74. Khoo J, Hsiang JC, Taneja R, et al. Randomized trial comparing effects of weight loss by liraglutide with lifestyle modification in non-alcoholic fatty liver disease. Liver Int. 2019;39(5):941-949.

75. Athyros VG, Polyzos SA, Kountouras J, et al. Non-alcoholic fatty liver disease treatment in patients with type 2 diabetes mellitus; new kids on the block. Curr Vasc Pharmacol. 2020;18(2):172-181.

76. Garvey WT, Mechanick JI, Brett EM, et al. American Association of Clinical Endocrinologists and American College of Endocrinology comprehensive clinical practice guidelines for medical care of patients with obesity. Endocr Pract. 2016;22 Suppl 3:1-203.

77. German MN, Lutz MK, Pickhardt PJ, et al. Statin use is protective against hepatocellular carcinoma in patients with nonalcoholic fatty liver disease: a case-control study. J Clin Gastroenterol. 2020;54(8):733-740.

78. Athyros VG, Boutari C, Stavropoulos K, et al. Statins: an underappreciated asset for the prevention and the treatment of NAFLD or NASH and the related cardiovascular risk. Curr Vasc Pharmacol. 2018;16(3):246-253.

79. Pelusi S, Petta S, Rosso C, et al. Renin-angiotensin system inhibitors, type 2 diabetes and fibrosis progression: an observational study in patients with nonalcoholic fatty liver disease. PLoS One. 2016;11(9):e163069.

80. Lee Y, Doumouras AG, Yu J, et al. Complete resolution of nonalcoholic fatty liver disease after bariatric surgery: a systematic review and metaanalysis. Clin Gastroenterol Hepatol. 2019;17(6):1040-1060.e11.

81. Mosko JD, Nguyen GC. Increased perioperative mortality following bariatric surgery among patients with cirrhosis. Clin Gastroenterol Hepatol. 2011;9(10):897-901.

82. Loomba R, Lim JK, Patton H, et al. AGA clinical practice update on screening and surveillance for hepatocellular carcinoma in patients with nonalcoholic fatty liver disease: expert review. Gastroenterology. 2020;158(6):1822-1830.

83. Perumpail BJ, Khan MA, Yoo ER, et al. Clinical epidemiology and disease burden of nonalcoholic fatty liver disease. World J Gastroenterol. 2017;23(47):8263-8276.

84. Grundy SM, Brewer HB Jr, Cleeman JI, et al. Definition of metabolic syndrome: report of the National Heart, Lung, and Blood Institute/ American Heart Association conference on scientific issues related to definition. Circulation. 2004;109(3):433-438.

85. International Diabetes Federation. IDF consensus worldwide definition of the metabolic syndrome. Brussels: International Diabetes Federation. 2005 